\title{
Innovation in Urban Mobility as an Urban Solution towards More Sustainable Cities: The Case of Informal Urbanization
}

\author{
Ahmed Khaled Ahmed Elewa ${ }^{1}$
}

\begin{abstract}
The main cities of emerging and developing countries (MCED) witness a growing economy accompanied by the continuous growth of its urban population and the chaotic urbanization, that is why the phenomenon of informal urbanization areas (IUA) is often associated with the MCED, IU areas generate a daily urban transport flows that contribute to multiple urban problems, mainly socio-economic issues, which impact the quality of urban life in negative way. The argument of the study refers to the possibility of achieving more sustainable cities through the using of innovation in UM (UM) as an urban solution. The study based on a theoretical study to define the intended meaning of innovation in UM, as well an empirical study through the analyzing of selected cases. The findings showed through lessons from practice that the using of innovative UM solutions is a sustainable upgrading approach that can contribute to achieve a better quality of urban life in the MCED with IU areas, also clarified the necessity to not to rely on this approach as a dominant approach but in integrated way with other traditional upgrading approaches, finally innovation in UM is not limited to the using of advanced and high tech solutions.
\end{abstract}

Keywords: Innovation, Urban mobility, Sustainable cities, Informal urbanization

\section{Introduction}

The importance of UM as an urban solution for achieving sustainable urban development has increasingly broaden hence Planning for UM has become commonplace in recent decades, according to the UNHABITAT it is a key dynamic of urbanization regarding its nexus to both the urban spatial structure of the city as well as its transport system., in 2009 the European Commission (EC) adopted an action plan of UM that sought to achieve sustainable urban development. However yet cities in developing world still away of the realizing the importance of adopting an advanced UM strategy, they still suffer of their local urban prior issue which is the chaotic urbanization that accompanied with incompetence of its UM system, and the spreading of vast IUA, moreover the available theories and empirical experiences of using UM to achieve sustainable urbanism were developed in the developed world. Even the contemporary studies regarding UM are seeking the priorities of the cities of developed world, whereas the current trend is to transform UM process into a sustainable system (as a global demand to mitigate the negative impact of the GHGs emissions) and of course to enhance the economic performance. However in the developing world and majority of emerging countries the priority regarding UM is yet limited to establish a stable UM system to face the continues chaotic urbanization and the spread of IUA. Thereby there

${ }^{1}$ Department of Architecture, Faculty of Fine Arts, Helwan University, Egypt; Associate Professor of Town planning and Architecture Design 
is a need to a holistic rethinking regarding how to deal with UM process as an urban solution that can contribute to more sustainable cities, notably in the case of MCED that suffers of IUA.

\section{The Nexus between Urban Mobility and Sustainable Urban Development}

UM refers to the physical movement of persons and goods in urban communities, whereas increased mobility increases accessibility (Litman, T., 2017), from this point of view UM concerns the urban transportation system which plays a crucial role in urban development, it acts as the circulatory system that connects city regions, it provides the mobility of people and goods through it, and this is why there is a growing consensus among specialists, researchers and the international organizations concerned with development on the positive multiple roles of UM towards achieving a high quality of urban life. According to Starkey and Hine there is a clear nexus between the top ranked cities in urban quality of life and the existing of high quality urban transport systems (Starkey P., Hine J., 2014), also according to the united nation department of economic and social affairs (UNDESA): "the evidence shows that cities ranking at the top of surveys measuring urban quality of life have high quality urban transport systems" (UNDESA, 2012). This logistic role of UM in cities explains the nexus that links it with urban development, notably in the case of the MCED, where urban accessibility is a significant problem particularly for the IUA as they in most cases located in marginalized and peripheral sites of cities, "Transport plays a crucial role in urban development. Especially in cities of the developing world" (UNDESA, 2012), hence in the case of less developed urban communities an efficient advanced UM system can provide urban solutions for most prior issues of urban life in IUA of the MCED, which is to deal with urban poverty issues and the urgent need for sustainable urban development, "enhanced mobility for the poor and vulnerable groups is one of the most important preconditions for reducing poverty and transitioning towards sustainable development" (Starkey P., Hine J., 2014). Enhanced UM was identified by the United Nations (UN) as the major building blocks of sustainable development (UNHSP, 2013), also Litman noted the same concept regarding the importance of an advanced UM which has significant economic, social and environmental impacts (Litman, T., 2008). Obviously in light of the previous debate there is a strong bond that links urban development with UM.

\section{The Need for Innovation in Urban Mobility in the Case of IUA}

This study focuses on the case of IUA which often associated with the MCED, in such urban communities (with high population density, socio-economic challenges) a daily mass flows of people and goods are generated, causing multi-dimensional problems, mainly socio-economic issues that related to UM, in addition to the environmental issues that often considered as secondary priority. Coping with this special case needs holistic and specific solutions, that do not impede the local economy growth but to contribute to community prosperity while reducing its negative impact on the environment, in other words there is a need for innovative solutions in the case of IUA. Hence enhanced UM solution through innovation would be more effective, the use 
of innovation in development is a current trend that is popular among institutions involved in development issues, for example the organization for economic co-operation and development (OECD) promotes the necessity of using innovation in special cases of development, "Innovation can make a difference in addressing urgent developmental challenges" (OECD, 2012), as well the UN through the recent decade has promoted several times the importance of innovation as a solution for a sustainable urban development "Science, technology and innovation can help achieve sustainable urban development by taking into account the economic, environmental and social dimensions of urbanization" (UN, 2013), UN has stressed on the importance of science, technology and innovation (STI) for economic growth and sustainable development in the Addis Agenda (UN, 2016), another regional example from the European union $(\mathrm{EU})$ report which conducted by the $\mathrm{EC}$ was in line with the UN report regarding the need for innovation in UM in order to provide urban solutions that achieve compatibility between the economic growth and the need to mitigate the negative impact of the UM process as it is a main contributor to the GHGs emissions, according to the EC the achievement of this goal requires innovation in UM solutions "The challenge is to respond to citizens' requirements for accessible, reliable, and safe transport. Meeting these challenges requires forward looking policies that incorporate innovative measures to meet pressing societal challenges and environmental constraints" (EC, 2013). Evidences from practice showed the crucial role of innovation in achieving sustainable and economic urban development, The OECD highlighted this concept regarding the importance of building-up of innovation capacities in developing countries as it has already played a central role in the growth dynamics of successful cases of emerging countries through the last two decades (OECD,2012), cities like Cairo, Lagos, Mumbai, Nairobi are in urgent need for an advanced UM system that based on building up a suitable local innovation capacity in the field of UM.
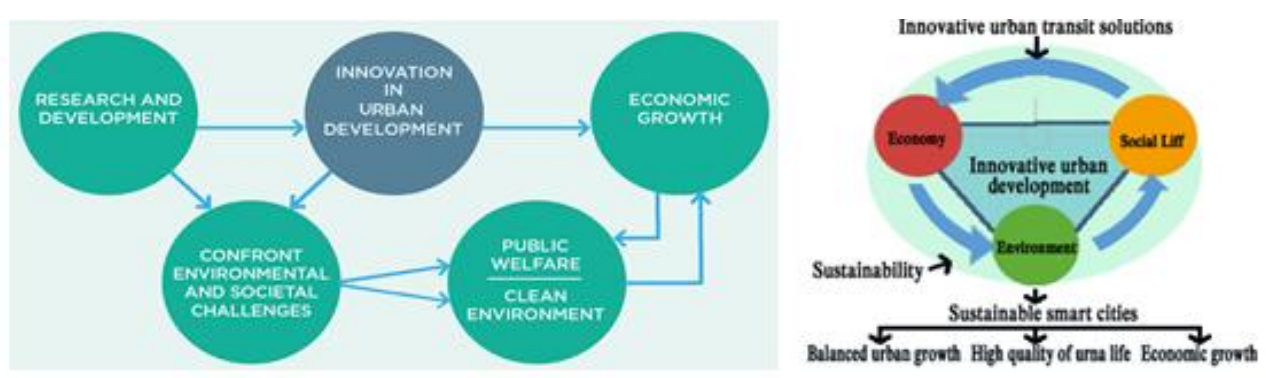

Figure 1: (Left) how innovation contribute to sustainable urban development, source: OECD, 2004 edited by author. (Right) the nexus innovative urban mobility solutions and the achievement of a bigh quality of urban life

\subsection{The Intended Meaning by Innovation in Urban Mobility in this Study}

Innovation in this study refers to solutions that have both socio-economic and environmental advantages that fit the characteristics of each case individually. UM innovation index (UMII) has defined innovation in UM as: "The implementation of a new or significantly improved product, process or organizational method. Innovations do not have to be game changers or new worldwide solutions, as innovation is contextual" (UMII, 2017), this definition is on line with the intended meaning in this study, which is a broaden understanding of 
innovation that is not only limited to be a totally new product or method or just about using imported high technology tools and products. Indeed innovation through the last two decades has played a pivotal role in economic development in many successful cases of emerging and developing countries, innovation in urban development has a broaden meaning that include new vision of using common solution. Hence innovation has various types that each type has its criteria and requirements according to each case conditions, moreover each case is passing through different stages of development from a developing stage to emerging stage and finally to a developed stage see table1.

Table1: The stages and types of innovation, source (OESD, 2012), edited by author.

\begin{tabular}{|c|c|c|}
\hline $\begin{array}{l}\text { Country } \\
\text { category }\end{array}$ & Mechanism/objective of innovation & $\begin{array}{l}\text { Type/source of innovation and } \\
\text { main agents involved }\end{array}$ \\
\hline \multirow{2}{*}{ 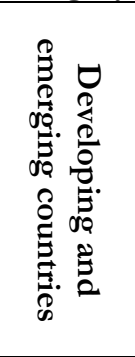 } & $\begin{array}{l}\text { Adoption requires adaptation: Innovation } \\
\text { needs to respond to specific "local" conditions } \\
\text { for outcomes. }\end{array}$ & $\begin{array}{llr}\text { Incremental innovation based on } \\
\text { foreign } & \text { innovations } & \text { and } \\
\text { technologies. } & & \\
\end{array}$ \\
\hline & $\begin{array}{l}\text { Inclusive innovation: for/by low- and middle- } \\
\text { income households to improve welfare and } \\
\text { access to business opportunities. Examples: } \\
\text { India (nano cars; grassroots innovation), mobile } \\
\text { banking services. }\end{array}$ & $\begin{array}{l}\text { Incremental innovation based on } \\
\text { foreign technology and/or local, } \\
\text { traditional knowledge generated "out } \\
\text { of necessity" Social innovation } \\
\text { helping to introduce technical } \\
\text { innovations in communities. }\end{array}$ \\
\hline \multirow{3}{*}{ 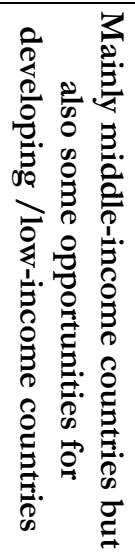 } & $\begin{array}{l}\text { Build up innovation capacities that will be key } \\
\text { for reaching the world technological frontier in } \\
\text { many industries, esp. relevant to avoid "middle- } \\
\text { income traps" Example: Korea increased R\&D } \\
\text { efforts in the } 1990 \text { s }\end{array}$ & $\begin{array}{l}\text { Incremental and radical innovation } \\
\text { capacity to compete with leading } \\
\text { world innovators. }\end{array}$ \\
\hline & $\begin{array}{l}\text { Address environmental, health and social } \\
\text { challenges through global innovation efforts } \\
\text { and local efforts to address them. Example: } \\
\text { Innovations concerning soil }\end{array}$ & $\begin{array}{l}\text { Major innovations and scientific } \\
\text { research conducted in global } \\
\text { partnerships but also marginal } \\
\text { innovations to address welfare of } \\
\text { poor people. }\end{array}$ \\
\hline & $\begin{array}{l}\text { Build-up niche competencies i.e. growth/ } \\
\text { exports in sectors of comparative advantage. }\end{array}$ & $\begin{array}{l}\text { Incremental innovations based on } \\
\text { applying foreign innovations and } \\
\text { technologies strategically to support } \\
\text { industrial development. }\end{array}$ \\
\hline
\end{tabular}

\subsection{Domains of Innovation in Urban Mobility for IUA Case}

As urban nobility copes with multi-dimensional aspects, there is a need to determine the main suitable domains that fits with the case of IUA in the MCED. Whereas this special case need its own criteria regarding the domains of innovation in UM, this criteria depends on the broaden definition of innovation in this study, So cities in less developed countries need to investigate innovation solutions that are not rely on unavailable technologies. Based on the reports and researches of various organizations, institutes and research centers there are two main domains in terms of innovation in UM solutions, the first domain is innovation in transportation modes, the second domain is about decision making regarding UM planning, in addition to some other supplementary 
domains that integrate with the main domains in order to improve the process of UM, for instance the innovation in using the information technology in enhancing the UM processes, for instance the using of the installation of surveillance systems on vehicles of a collective transport system, and at public transport stops, which improve the security performance of the public transportation system (CIVITAS, 2014), (OESD, 2012), (EC, 2013), (UN, 2016), (UMMI, 2017).

\subsubsection{Innovation in Transportation Modes}

This domain of innovation in UM includes all the modes of transportation (Publicprivate) and (motorized and non-motorized), it focuses mainly on the enhancement of the transportation modes performance, to be safer, faster, more economic, less GHGs emissions, less noise, in other words to shift towards sustainable transportation modes which include the shift towards electric-powered vehicles or what is so called (Emobility) away from the use of fossil fuels and carbon gas emissions (FIA, 2011). However for the purpose of this study this domain focuses on the public transportation modes and non-motorized modes as well, from another perspective which investigate the possibility of rethinking of using common public transportation modes and nonmotorized modes in new innovated way that fits the special criteria of the IUA in the MCED.

\section{A. Innovation in public transportation modes}

The IUA is the most significant phenomena in the MCED that make the need for innovation in public transportation modes more initial demand, as it can deal with diverse UM problems which is often associated with these areas, in addition to the other common UM problems that is linked to the MCED. Innovation in public transportation modes is not limited to use the latest advanced modes in terms of faster, safer, and lower carbon emissions, but also to select suitable mode that fit the local conditions of each case individually in order to cope with the following issues:

- The social needs: where rapid decline of mobility and in accessibility due to the marginalized sites of these areas are common barriers, an innovative public transport mode can solve such problems, there are many examples from Latin America cities.

- The vast growing ratio of car ownership and other private transit modes notably in emerging cities in Aisha, such as motor bikes, which is the main cause of congestion, the use of innovative public mass transport mode is the best alternative to individual private car (Cervero, R., 2013).

- The bad quality of urban life: An innovated public transportation mode reduces the daily trips, which means less traffic congestion, less energy consumption, less emissions, a better quality of urban life and more sustainable cities.

-The economic barrier in the MCED: Investing in establishing a innovated public transportation modes is more economic strategy than to invest in more infrastructure for individual modes of UM, according to WHO: "Road building: a dominant transport investment Much of the urban transport investment in developing countries in the decade of the 1990s was focused on road improvements (WHO, 2009). 

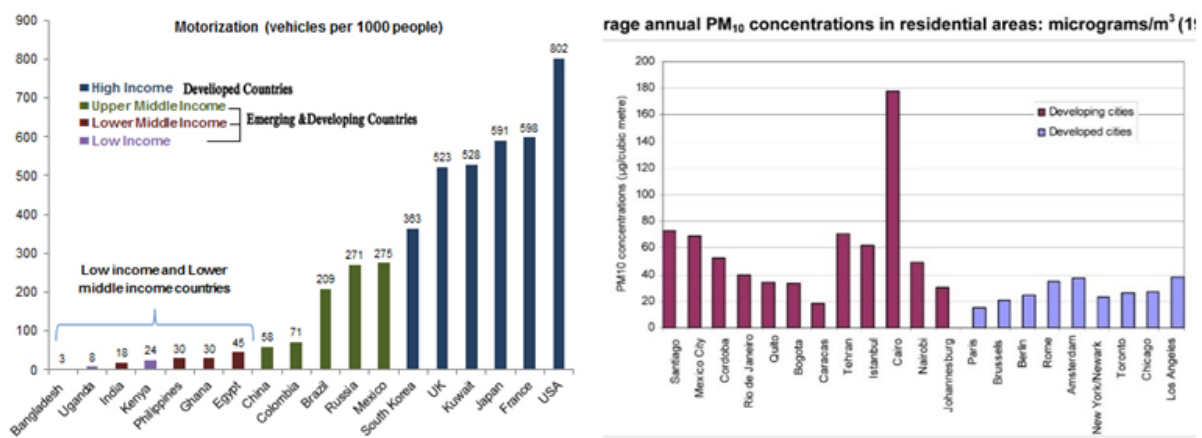

Figure 3: (Left) Motorized vehicles (mainly private cars) per 1000 people, a comparison between selected cases of developing emerging countries and developed countries, World Bank. (Right) Air pollution by PM that impact the quality of urban life, a comparison between selected cases of developing emerging countries and developed countries, UN, World development indicators.

\section{B. Innovation in non-motorized transport modes}

Mainly refers to modes of transit solutions that depends on human power, it include walking, cycling, and the other modes that have wheels but no engine such as cycle rickshaw in India and South east Asia, which also called pedicels in other countries, and freight tricycles (Servaas, M., 2000). According to WHO "Walking and cycling networks support a range of positive and synergistic social, environmental and development benefits" (WHO, 2009), thus this is why non- motorized transport (NMT) modes can provide innovated UM solutions in the case of IUA of MCED, whereas these areas often marked by urban poverty, meanwhile non-motorized are economic and represents available technology modes for such an urban context. Moreover in some cases of informal urbanization areas the urban tissue is very complicated, and mainly consists of narrow alleyways, only non-motorized modes can access this areas to provide accessibility to the residents to the main arteries and public transportation stations, which make cities more livable, meanwhile it mitigates the social exclusion of the poor residents, non-motorized transit solution in this special case act as innovated intermediate transit for poor residents to the public transportation system of the city. Also these modes are sustainable modes that are friendly to the environment (zero emissions modes), recently some European cities promoted the concept of bicycle sharing systems, such as Paris's Velib system with 21 thousand bicycles available throughout the city (Lin J., et al, 2017).
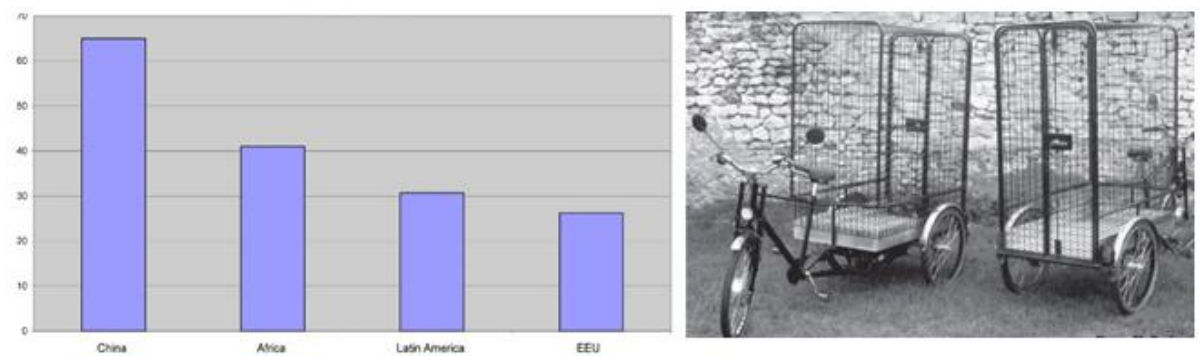

Figure 4: (Lift) Non-motorized transport in selected countries and regions source: Kenworthy and laube, 2002, (right) examples of enhanced non-motorized modes by local low technology, source NICHES.com 


\subsubsection{Innovation in Decision Making Regarding Urban Mobility Planning}

Innovation in decision making regarding UM planning plays a key role in the successes of the implementation of UM enhancement plans, lessons from practice in various cases of MCED notably from Latin America have clarified how innovation in decision making can contribute to a better sustainable urban communities particularly the cases of IUA (UNHABITAT, 2012). The proses of making decision by local authorities is a real challenge as they need to balance between responding to community's needs for urban accessibility via a reliable and safe transport system, that meet pressing societal requirements and environmental constraints (EU, 2013), which is a more complicated decision in the case of IUA in MCED, whereas environmental constrains comes as secondary priority and sometimes to be neglected totally. Moreover in some cases of UM plans the role of decision making regarding UM plans was initial and act as integrated urban solution, it is all about the choosing of suitable proposal that fit the requirements of each case individually, for instance the establishing of a Bus Rapid Transit System (BRT) require an UM plan that is based on strategies and policies that promotes urban development of higher density along mass transit corridors (Cervero, R., Guerra, E., 2011), such strategy require an urban context of highly density and a determined urban growth corridor which is only suitable for specified cases, such as the case of Curitiba city BRT system in Brazil, which was an innovated decision that considers as a milestone in the UM history, this type of innovated solutions required innovation in decision making in addition to the political will.

\section{Study Cases}

Cases were selected to meet a specific criteria that illustrates the main assumption of this study, which is possibility to enhance the quality of urban life in IUA in MCED towards more sustainable cities by using innovative UM solutions as urban development approaches.

\subsection{Medellin Case (Innovative Public Transportation Solution)}

Medellin is an example of the MCED, it is the second largest city in Colombia, like many other main cities in Latin America, the city outskirt suffer of the IUA, which located in marginalized sites, due to the city's unique geography the informal settlements is located on the steep hill that mark its topography. This IUA area had a bad quality of urban life, mainly as a result of inaccessibility to the formal city, as the area is not linked to the public transportation system it suffered of isolation and remoteness, meanwhile the informal area have a high population densities reached 500 inhabitance per hectare, this problem negatively impacted socio-economic activities through urban poverty, social segregation as well the isolation site of the settlement was the major reason that make it one of the most violent and socially fragmented places in the world, in addition to other common issues in such an urban context such as the lack of public spaces and facilities for walking and biking, and the lack of basic infrastructure (GTZ, 2014), 

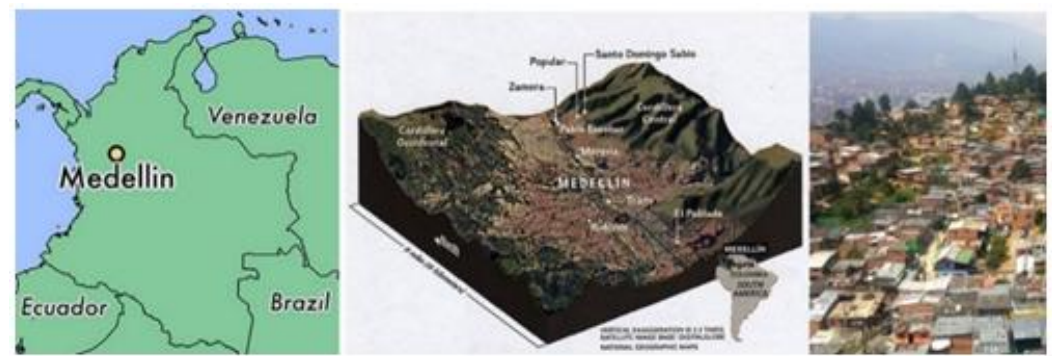

Figure 5: Medellin map, the special topography of Medellin, and its marginalized site, source: mappery.com/Medellin-physical-oblique-map

A development plan was implemented called the integral urban project (PUI) from 2004 to 2011, aimed mainly to improve the quality of urban life through an integral strategy that focused on strengthen social and economic cohesion within the City's boundaries by linking the area to the public transportation system through an innovated UM solution. The PUI depended on the necessity of connecting the marginalized IUA settlement to the public massive transportation system (Metro) in Medellin, this connecting process was through a new innovative massive mono-cable system known as Metro cable in 2004 (Blanco, C., Kobayashi, H., 2009), this innovative system was designed to be integrated with the main public mass transit system of the city, as well it managed to improve accessibility for pedestrians through a smart innovated infrastructure facilities that provide escalators and lifts enabled the accessibility of hillside developments to the Metro cable stations and city center as well. Medellin's Metro cable system managed to connect poor residents to their city and to put innovated UM solution.
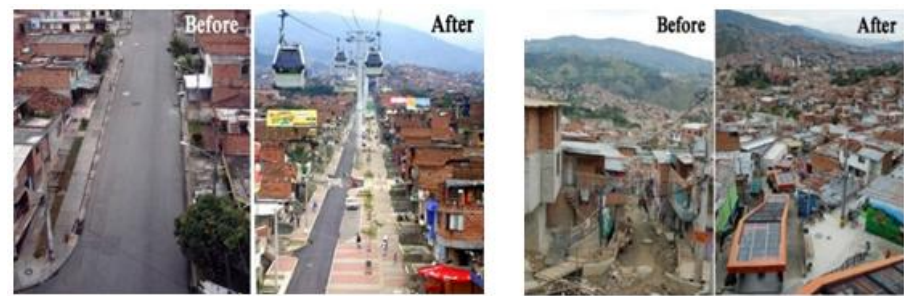

Figure 6: Medellin before and after the PUI that depended on innovative public transit solution, source: GTZ, 2014, edited by author

\subsubsection{The Domains of Innovation in Urban Mobility Solutions}

Medellin case represented some of the innovation domains regarding the UM solutions, as presented below:

-Innovative public transportation mode by using of the common Metro cable system in a new way as a massive public transport system, it represented an innovative solution that did not require a high-tech new solution. Moreover this innovative public transport solution managed to solve the main urban problem of connecting the marginalized isolated IUA settlement with the city in addition to provide multiple socio-economic benefits that improved sustainability of the urban community.

-Innovation in decision making by the local authority regarding the urban development 
plan (PUI) and the using of UM solution as a supplementary approach that took in consideration both the passengers and the pedestrian requirements, the urban design provided walking accessibility through escalators and lifts in order to overcome the topography barrier, as well the plan supported the walking as a non-motorized transport mode solution through the creation of accessible inclusive paths and public spaces.

\subsubsection{Lessons from Practice (Medellin Case)}

Medellin case presented many lessons from practice as clarified below:

-The case showed the strong correlation that linked the innovated UM solutions with the achievement of a high quality of urban life, thus this is why UM solution can be used as sustainable urban development approach notably in the case of the IUA.

- Innovation in UM solution is not only limited to the using of new or high-tech solutions, but it has a broaden understanding that contribute to the rethinking of how to use common transportation modes in a new smart way.

- The key role of innovation in decision making and the political well in implemented such new innovated ideas.

- Innovated Public transportation is the backbone of any sustainable UM system particularly in particular in the case of IUA in the MCED.

\subsection{Delhi Case (Non-motorized Mode Solution, Cycle Rickshaw)}

Delhi officially is the National Capital Territory of Delhi (NCT), so it is a city and a union territory of India, as well the second largest city in India in population and economic power after Mumbai (government of India, 2017). Like other MCED, Delhi is witnessing a rapid urbanization growth, the most significant urban problem is the spreading of IUA inside and around the city, also the traffic congestion as a result of the increasingly numbers of private cars and motor cycles.

The case is about the using of a non-motorized mode in Delhi called Rickshaw (a three wheels cycle used as a taxi for max. two passengers or cargo) to deal with UM issues in order to promote a sustainable transport mode, which is a common UM solution that depends on human power, officially there are around 100,600 traditional cycle rickshaws in Delhi (DES, 2010). This transportation mode is initial for the socio-economic activates in the IUA in Delhi as it has a multiple benefits:

- It acts as an intermediate low-cost public transport solution to the poor residents from their informal settlements to city main arteries and other public transport system stations, "cycle rickshaws have become a feeder service for the metro and bus stations, and can be found queued up outside many metro stations in Delhi" (George, PT., 2013).

- Indispensable mode of transport for people and goods inside the narrow streets and alleys of the informal settlements, it plays a pivotal role in providing point-to-point connectivity, and connect the inner areas of the IUA settlements with the formal city.

- Rickshaw plays an essential role in providing honest means of living to the poor unskilled labors of the informal settlements, as it needs a low operating costs, it is a significant sector of the informal labor market without any financial investment or support from the local authorities in Delhi.

- A non-motorized public transport solution that depends on human power so it is friendly to the environment which is important in city suffers of air pollution. 

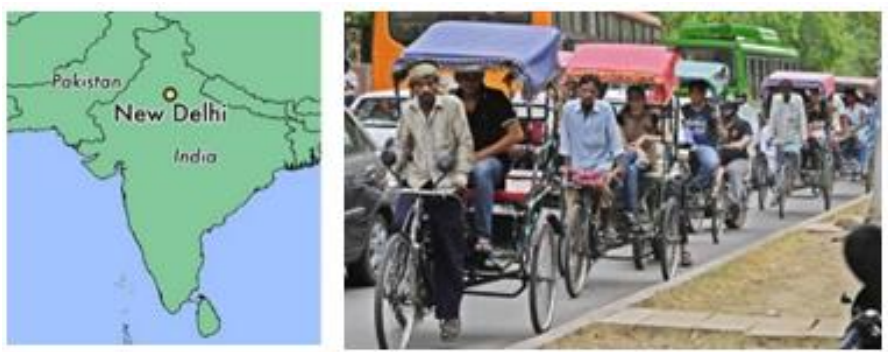

Figure 7: Delhi map and cycle rickeshaws in a Delhi street, source: delhiinmotion.com

However an investment criteria that was suggested by various local financial institutions have encouraged a policy of banning rickshaws from the busiest city center roads, but campaigns were conducted by NGOs and concerned citizens against such banning policies, in 2010 Delhi's High Court declared that rickshaw license quotas were unlawful in a landmark ruling (ITDP India, 2008). Recently some projects and programs were conducted by local institutions that aims mainly to improve the Rickshaw performance, hire systems, in addition to programs to train drivers to improve their skills regarding dealing with traffic issues such as how to avoid creating congestion, and to give better customer service, such as:

-Indian cycle rickshaw modernization project launched by ITDP in 2006, the project comprised a research and development program that focuses on innovated design of the rickshaw to be lighter, comfortable for both the operator and costumer, also a training program for drivers regarding traffic issues in order to improve safety (ITDP India, 2008). As well ITDP has promoted the use of rickshaws as feeders to Delhi's public transport system of metro and BRT lines.

- Green cab project conducted by Delhi Integrated Multi-Modal Transit System (DIMTS), this project aims to improve the rickshaw service by offering a "dial-arickshaw" a door to door and door to or from the BRT stations service, to be similar to conventional taxi offices, as well the project will depend on improved rickshaw vehicles, more lighter and comfortable, and the service should be fully integrated into the public transport network (DIMTS, 2008).

- Moreover a new improved version of rickshaw that depends on Battery-assisted rickshaws have been trialed, " these enhanced type have a range of 72 miles and a top speed of 20 $\mathrm{km} / \mathrm{h}$, helping operators to cover greater distances for less effort. Charging at solar-powered stations is required every 6-7 hours. (Treehugger, 2008). Already 4,000 battery-powered rickshaws were introduced by the Municipal Corporation of Delhi under a Public-Private Partnership deal, as part of a plan to replace traditional rickshaws (Brauninger, M., et al, 2012).
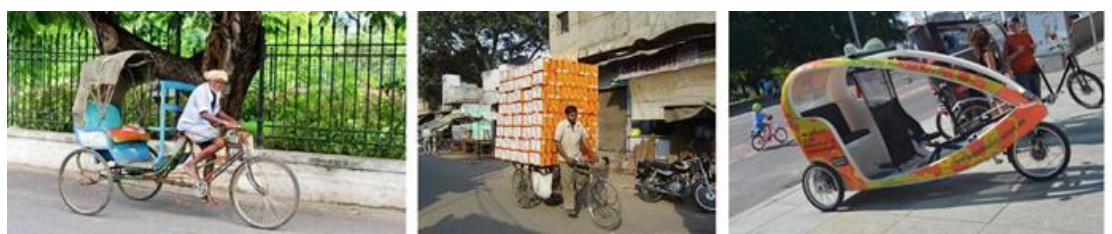

Figure 8: Cycle rickshaws in Delhi are used for both passengers and cargo, the last one from right is an enhanced version in Berlin, source: india.com, enidhi.net, wikiwand, edited by author. 


\subsubsection{The Domains of Innovation in Urban Mobility Solutions}

Delhi case showed that innovation in UM solutions can contribute to the rediscovering of the potentials of local common and conventional UM solution, the improvement of the rickshaw performance in Delhi case was conducted through the available local experience that managed to revive rickshaws to be fully integrated into the public transport network, as well to use the power of research to introduce new innovative version that depends on battery power.

\subsubsection{Lessons from Practice (Delhi Case)}

This case illustrated how innovation in UM solution can provide practical solution to the UM problems that associated to the IUA in the MCED, also showed how innovation managed to turn the rickshaw which is just a common local non-motorized transport mode into a innovative UM solution that deliver multiple benefits to the socioeconomic system in Delhi, as well it is a good example of the integration of a common local non-motorized transport mode and mass public transport system. Moreover the case showed the essential role of the decision making and how the implemented policies sometimes impact the real societal and economic needs of the urban community, and the important role of the local institutions and NGOs, thus this is why any successful plan or project must take in consideration the whole stake holders, notably the decision makers and dwellers in the case on IUA of the MCED.

\section{Conclusion}

The study cases presented lessons from practice that clarified how innovation in UM can deliver solutions that plays essential roles not only in solving IUA prior urban issues, but it also contributes to other socio-economic needs through its multiple roles, as well it proved that the successes of urban development plans that aims to achieve a more sustainable urban life can be achieved through using innovative UM solution through various domains, also clarified that innovation in UM solutions in the case of MCED is not limited to the using of advanced or high technology solutions, but it has a broaden meaning that depends on the need for a total rethink of the whole process of UM to rely mainly on the available local potentials and available technology, to be reliable, to respond to the real needs and priorities of the dwellers of IUA, which is to provide an efficient and safe UM solutions that facilitate the daily socio-economic activities as a priority, meanwhile to respect the environmental constrains. Innovation in UM provides urban solutions that have the ability to make cities more sustainable, however evidences from practice show that the using of UM solutions as an urban development approach should be influenced by the local specificity of each case, this mean that each case regarding its local socio-economic criteria need its own type of innovative UM solution, in other words what is suitable to the cities of developed countries is not often suitable in the case of MCEDs. 


\section{References}

Blanco C., Kobayashi H. (2009). Urban transformation in slum districts through public space generation and cable transportation at Northeastern area: Medellin, Colombia. The journal of international social research, Vol. 2/8, summer 2009.

Brauninger M. (2012). Achieving sustainability in urban transport in developing and transition countries, On behalf of the Federal Environment Agency (Germany), Retrieved 24 June 2017 from: http://www.uba.de/uba-info-medien-e/4239.html

Cervero R., Guerra, E. (2011), Urban Densities and Transit: A Multi-dimensional Perspective, Institute of transportation studies, University of California.

Cervero R. (2013), Transport Infrastructure and the Environment: Sustainable Mobility and Urbanism, Institute of urban and regional development IURD, University of California, Berkeley, October 2013.

CIVITAS (2014), Innovative urban transport solution, makes the difference, How 25 cities learned to make urban transport cleaner and better.

DES (2010). Delhi Statistical Handbook 2010, Delhi, Directorate of Economics \& Statistics, Government of National Capital Territory of Delhi.

DIMTS (2008). Smart and Connected Transport - A Case Study of Delhi. Delhi, Delhi Integrated MultiModal Transit System Ltd.

EC (2013), Innovation in UM Policy making and planning, communicating transport research and innovation.

EC (2016), Quality of life in European cities 2015, regional and urban policy, European commission, January 2016.

FIA (2011). Towards E-mobility, the challenge ahead, Federation Internationale de l'automobile (FIA), Retrieved $26 \quad$ June 2017

from: https://www.lowcvp.org.uk/assets/reports/emobility_full_text_fia.pdf

George PT. (2013). Pedaling for Bread: Rickshaw Pullers of Delhi Struggle for a Living, Retrieved 24 June 2017 from:https://www.ritimo.org/Pedaling-for-Bread-Rickshaw-Pullers-of-Delhi-Strugglefor-a-Living

GIZ \& ICLEI (2014), Medellin, Colombia, the Integral Urban Development Project: fighting crime with urban interventions.

Government of India (2017). The Constitution (Sixty-Ninth Amendment) Act, 1991, Ministry of Law and Justice, Retrieved 24 June 2017 from: http://indiacode.nic.in/coiweb/amend/amend69.htm

ITDP India (2008) Cycle rickshaw and Cycling Advocacy in Delhi.

Lin J., Wang N., \& Feng Ch. (2017), Public bike system pricing and usage in Taipei, International Journal of sustainable transportation, Volume 11, 2017, issue9, pages 622-641.

Litman, T., (2008). A Good Example of Bad Transportation Performance Evaluation: Critique of, "Transportation Performance of the Canadian Provinces", Victoria Transport Policy Institute.

Litman, T., (2017). Evaluating Accessibility for Transportation Planning Victoria Transport Policy Institute, Measuring People's Ability to Reach Desired Goods and Activities, Victoria Transport Policy Institute.

Mieg H. (2010), Sustainability and innovation in urban development: concept and case, journal of Sustainable development, Volume 20, Issue 4, July/August 2012, Pages 251-263.

OECD (2012), Innovation for Development, a discussion of the issues and an overview of work of the OECD directorate for science technology and industry, Organization for economic co-operation and development (OECD)

Santiago R. (2017), The Role of Urban Infrastructure in Supporting Transit-Oriented Development, Arizona state university, March 2017.

Servaas, M. (2000). The significance of non-motorised transport for developing countries, strategies for policy development (final report), Utrecht, the Netherlands

Starkey P. \& Hine J. (2014), Poverty and sustainable transport, how transport affects poor people with policy implications for poverty reduction, a literature review. UN-Habitat, and the Overseas Development Institute (ODI), October 2014. 
Treehugger (2008). Solar-Powered Electric Cycle Rickshaw Debuts in Delhi, Retrieved 24 June 2017, from: http://www.treehugger.com/files/2008/10/solar_powered_r_3.php

UMMI (2017). UM innovation index, the Roads \& Transport Authority of Dubai (RTA) and implemented by UITP in partnership with Future Cities Catapult.

UN (2009), Creating an Inclusive Society: Practical Strategies to Promote Social Integration. Retrieved 28 June 2017 from:http://www.un.org/esa/socdev/egms/docs/2009/Ghana/inclusive-society.pdf

UN (2013), Science, technology and innovation for sustainable cities and peri-urban communities, Commission on Science and Technology for Development, Retrieved 26 June 2017 from: http://unctad.org/meetings/en/SessionalDocuments/ecn162013d2_en.pdf

UN (2014). World Urbanization Prospects, Highlights, 2014 revision.

UNDESA (2012). Shanghai Manual - A Guide for Sustainable Urban Development in the 21st Century, Chapter 4 - Sustainable urban transport, United Nations Department of Economic and Social Affairs (UNDESA).

WHO (2009), Healthy Transport in Developing Cities, Health and Environment Linkages Initiative (HELI), United Nations Environment Programme, World Health Organization, Geneva, 2009. 